\title{
Suzana E. Flores, Sfejsowani. Jak media społecznościowe wpływaja na nasze życie, emocje i relacje z innymi [Facehooked. How Facebook Affects Our Emotions, Relationships, and Lives], MUZA SA, Warszawa 2017, pp. 298
}

Everyone knows at least one person who has a Facebook account, and probably this person knows many such people. I suspect that most of us have been at least once a user of this social networking site. Facebook has captured our lives and it is often about adding photos, posts, sharing and forwarding information. Boldly we can say that we are 'facehooked'. How to understand this term? How to deal with this phenomenon? How to skilfully use Facebook to keep control over our lives? Dr. Suzana E. Flores in her book Facehooked. How Facebook Affects Our Emotions, Relationships, and Lives attempts to find the answers for these and other questions.

Social media is certainly an important part of our lives. Almost every Facebook user logs on to the portal every day, usually a few or even several times a day. We often start our day by looking at news on our profile, and we end up sending friends good night's wishes on the communicator. Our duties, work, leisure or relationships with people often suffer because of that. When we spend time staring at the screens of laptops, tablets or smartphones, we forget that real world is next to us, and the concert recorded on the phone and made available to friends on our profile is not the same thing as seen with our own eyes.

Dr. Suzana E. Flores, the author of the book Facehooked. How Facebook Affects Our Emotions, Relationships, and Lives, is a clinical psychologist with many years of experience. She obtained her education at Loyola University in Chicago (psychology assistant) and at Argosy University (doctorate in clinical

Department of Political System of Poland, Faculty of Political Science and International Studies, Nicolaus Copernicus University in Toruń, Poland, E-MAIL: natalia.gburzynska@op.pl. 
psychology). She worked, among others, as educational director of the Illinois Institute of Art and associate professor at the Chicago School of Professional Psychology. She has now a private practice in clinical psychology. In her professional career, she has been dealing with compulsive behaviors and addictions. In a peerreviewed publication, she shared her insights on the impact of social media on the lives of people regardless of their age. Dr. Suzana E. Flores also argues that social media is not responsible for threatening interpersonal relationships but our improper behavior can bring miserable results. Dr. Flores works on a daily basis with people who have agreed to share their experience on communicating through the Internet. Thanks to her knowledge and experience, she has been recognized as an expert in the field of Internet communications and she has been frequently invited as a commentator to many talk shows and news services.

The book Facehooked. How Facebook Affects Our Emotions, Relationships, and Lives consists of ten chapters, each of them is focusing on a different theme related to social networking. Dr. Flores discusses changes in interpersonal relationships in the digital age, the relationship between user profile photo and their identity, network privacy issues, new ways of establishing friendships, but also ending them, the challenges that are faced in the relationships (e.g., flirting on Facebook, statues of relationship and their importance in everyday life, as well as the phenomenon of stalking), dependence on social media and finally finding approval and understanding in the Internet environment. This manifests itself - morbidly - in focus on how many 'likes' and comments will appear under the post published or under the photo that was added.

It is worth mentioning the fact that the reviewed publication is not just a discussion of our life on the web. It is also linked - or perhaps above all - to the story of how the world and people have changed over the last dozen of years. Today anyone with a social networking account can express their views confidently, and by sharing their posts people can reach each other despite living thousands of miles away. Such an opportunity exerts a tremendous impact on society, which we do not always realize. In addition, the presence in the network builds in us the sense of obligation to constantly respond to notifications, respond to comments, or keep track of the news on the board. Facebook users often admit that they do not like, and even come to the situation that they are afraid of omitting some news or overlooking information.

Facehooked is a story about how young people make relationships with social networking sites such as Facebook, Snapchat, and YouTube. The author provides readers with a great deal of information on smartphone and Internet addiction, building young people's identity online, and the negative effects of excessive dis- 
semination of knowledge about themselves. In addition, Dr. Flores demonstrates the ways in which we can fight addictions. Thanks to the reading, we can diagnose ourselves or a loved one with this problem.

Through a story based on facts, the author has been able to show the impact the virtual world has on our lives. Very interesting - in this context - is chapter Relationship? It's complicated. The author discusses the principles of building relationships on the social networking site, and - more and more - the phenomenon of flirting via Facebook. Many of the people whose stories are quoted in this chapter do not take such a flirt seriously. Another problem related to the sphere of feelings is also quarrels and even breakups, due to the fact that one of the parties does not want to disclose on Facebook the fact that he or she met someone or got married, which causes the partner to believe in rejection, lack of acceptance or even shame induced by being in this relationship.

Dr. Flores' publication presents the opinions of social networking users, which is a great advantage. The author recalls the statements of the users about the use of the web, publishing private information or photos, but also their stories in which Facebook plays a large role. These described experiences are very hard or even inconceivable - for example, Anabella of Indianapolis described a story that happened to her, "the most awkward thing I've seen, looking at my stream of news on Facebook, was the photo of the baby in the coffin. Seriously, my friend made a picture of her three-month-old dead daughter and put it on her timeline" (Flores, 2017, p. 265). Another story was shared by Brian from Chicago: "I got a tendonitis in my thumbs from writing text messages and sitting on Facebook on my phone. A bit inconvenient situation, isn't it? Now, my thumbs hurt me as soon as I write something. Soon, they will be put on a stabilizer, so I guess I'll have to use voice control” (Flores, 2017, p. 271).

Both of the stories quoted above are, at first, so unbelievable. However, the thought that comes to mind is that we live in a world in which we lose true values, and the virtual world is mixed with the reality of social networking sites. Owing to the publication of Dr. Suzana Flores, we have the opportunity to realize this. Consequently, the reader can consider this book undoubtedly necessary and anyone who has a Facebook account should read it. During reading, the reader is often amazed by the fact that certain dependencies that occur in the book are also present in our lives, many of which we do not even realize. The author in a very sharp way explored the impact that social media has on our lives. Facehooked skilfully shows us the phenomenon of rapid development of communication technology on the web.

Dr. Flores' conclusions are certainly very relevant and provide a good starting point for further research into our presence on the Internet. Nevertheless, I would 
like to mention about a flaw that is present in that book. In my opinion, the author rated Facebook and our activity on it only from one side of it. The subtitle of the book is How Facebook Affects Our Emotions, Relationships, and Lives, and after reading it, it would seem that the impact is always negative. Facebook, meanwhile, is also a medium that helps in many situations - for example, the fund raising for sick people or victims of cataclysms. The publication lacks the glimpse of the other side, showing that social media - with the wise use of them - can bring a lot of benefits. At the end of the book, case studies have been cited - over 50 Facebook user stories. Among these dozens of stories there is no one in which the positive dimension of this social networking site is presented. Obviously - it is probably related to the thesis the author puts in her reflections, but if the subtitle points to a question: how social media affects our lives, it would be worthwhile, in my opinion, to point out the positive impacts. Otherwise, one can get the impression that the problem raised has been presented too shallow and even superficially.

In conclusion, it should be noted that the issues raised by Dr. Suzana Flores are certainly very up to date. The author showed us what trends we are dealing with and also drew attention to the power of social media in our lives. It is important to note that the book Facehooked is a compulsory reading - for sociologists, journalists, philosophers and cultural studies scholars, but also for all of us - Facebook users. The stories in the book may happen to us while viewing the news on our board.

Theses given in the publication are extremely thorough and accurate. I also think that they are an interesting starting point for further research - even in the context of comparison on how the social media affects people aged 30-40, who also know life without the Internet, and what impact it has on modern teenagers, growing up in reality where universal access to the network and our presence in it are obvious.

The reviewed book can also be of great interest to young people who are just searching for their identity, building it, and spend a great deal of their free time online. Through reading they can understand that, with similar emotions, other people also suffer from the experience. In addition, Facehooked helps people understand certain behavior patterns, making it much easier to fight them. Another group that may be interested in reading are psychologists who experience everyday problems with dependencies on phones, computers, or the Internet. The stories quoted in the book are potentially the stories they may encounter in their work. Parents of teens should also be aware of this reading - not only will they learn more about the world in which their children live, but they will also be able to better communicate with them due to better understanding of their concerns. 